\title{
The course of untreated anxiety and depression, and determinants of poor one-year outcome: a one-year cohort study
}

\author{
Ilse MJ van Beljouw ${ }^{1}$, Peter FM Verhaak ${ }^{*}$, Pim Cuijpers², Harm WJ van Marwijk³ ${ }^{3}$ Brenda WJH Penninx $x^{4,5,6}$
}

\begin{abstract}
Background: Little is known about the course and outcome of untreated anxiety and depression in patients with and without a self-perceived need for care. The aim of the present study was to examine the one-year course of untreated anxiety and depression, and to determine predictors of a poor outcome.

Method: Baseline and one-year follow-up data were used of 594 primary care patients with current anxiety or depressive disorders at baseline (established by the Composite Interview Diagnostic Instrument (CIDI)), from the Netherlands Study of Depression and Anxiety (NESDA). Receipt of and need for care were assessed by the Perceived Need for Care Questionnaire (PNCQ).

Results: In depression, treated and untreated patients with a perceived treatment need showed more rapid symptom decline but greater symptom severity at follow-up than untreated patients without a self-perceived mental problem or treatment need. A lower education level, lower income, unemployment, loneliness, less social support, perceived need for care, number of somatic disorders, a comorbid anxiety and depressive disorder and symptom severity at baseline predicted a poorer outcome in both anxiety and depression. When all variables were considered at the same time, only baseline symptom severity appeared to predict a poorer outcome in anxiety. In depression, a poorer outcome was also predicted by more loneliness and a comorbid anxiety and depressive disorder.
\end{abstract}

Conclusion: In clinical practice, special attention should be paid to exploring the need for care among possible risk groups (e.g. low social economic status, low social support), and support them in making an informed decision on whether or not to seek treatment.

\section{Background}

Anxiety and depression have serious consequences for patients, their family, and for society. However, many mental disorders remain untreated [1-8]. In general, undetected and untreated patients have less severe symptoms than detected patients who receive treatment [9-12].

It is important to take patients' preferences and views into account. Some patients can find a way to deal with their symptoms. There even are patients who do not perceive a mental problem, despite fulfilling the criteria for a CIDI-diagnosis of anxiety or depression, or who simply do not perceive a need for care $[13,14]$.

\footnotetext{
* Correspondence: p.verhaak@nivel.nl

${ }^{1}$ Netherlands Institute for Health Services Research, Utrecht, the Netherlands Full list of author information is available at the end of the article
}

In Moitabai's study [1], one third of untreated patients reported unmet needs, especially younger patients, higher educated patients and patients with insurance problems. In our own study [13], based on baseline data from the Netherlands Study of Depression and Anxiety (NESDA), we found that $25 \%$ of untreated patients with a current anxiety and/or depressive disorder perceived themselves as mentally healthy. Twenty-six percent had no perceived need for care, and $49 \%$ perceived a need for care which was not met, especially in patients from ethnic minority groups and patients with a lack of social support. It was found that subjects with an unmet perceived need for care reported equally severe and clinically relevant symptoms at baseline as subjects who received professional care. Patients without a perceived need had less symptoms than

\section{(Ciomed Central}

(c) 2010 van Beljouw et al; licensee BioMed Central Ltd. This is an Open Access article distributed under the terms of the Creative Commons Attribution License (http://creativecommons.org/licenses/by/2.0), which permits unrestricted use, distribution, and reproduction in any medium, provided the original work is properly cited. 
patient with a met or unmet need. This has been found in other studies as well [15].

It becomes problematic when untreated patients have a worse outcome than would be the case if they were treated. Rost et al. [16] found that undetected and untreated patients with major depression in primary care have poor outcomes compared with treated patients. In this study, however, untreated patients were followed up, regardless of their own perceived need for treatment.

To our knowledge, outcome of untreated anxiety and depression in patients with and without a self-perceived need for care has not yet been studied. As self perceived need for care might be an important modifier for the risk of not being treated, we will include this parameter while searching for consequences of not being treated and for determinants of possible poor outcome after not being treated.

\section{Aims of the study}

The aim of this study was to investigate the consequences of being untreated for an anxiety or depressive disorder at one-year follow-up, in patients with and without a need for care. In addition, determinants of a poor outcome in untreated patients were evaluated.

\section{Methods}

\section{Sampling and data collection}

All data used in this study were derived from the Netherlands Study of Depression and Anxiety (NESDA). NESDA is a multi-site naturalistic study, and aims at studying the long-term course and consequences of anxiety and depressive disorders for a period of eight years. The analyses presented in this study are based on the baseline (2004-2006) and one-year follow-up assessment. Procedures of NESDA are described in detail elsewhere [17]. The study protocol was approved centrally by the Ethics Review Board of the VU University Medical Centre, and subsequently by local review boards of each participating center.

In brief, respondents were recruited from 65 general practitioners (GPs) in the vicinity of the field sites (Amsterdam, Leiden, Groningen) using a three-stage procedure (see figure 1). Firstly, a random selection of 23,750 patients aged 18 to 65 years who consulted their GP in the last four months - irrespective of the reason for their visit - were sent a Kessler-10 screening questionnaire [18], measuring psychological distress, and five additional anxiety questions. The response rate was $45 \%(\mathrm{~N}=$ $10,706)$. Of this group, the 4,592 screen-positives were additionally screened during a brief telephone interview conducted by trained research staff, consisting of a short form of the Composite Interview Diagnostic Instrument (CIDI) [19]. Ultimately, 743 respondents who met the criteria for a six-month anxiety or depressive disorder (established by a full CIDI, and including a major depressive disorder, dysthymia, general anxiety disorder, social phobia, panic disorder or agoraphobia), and who were fluent in Dutch were included for the baseline assessment (T0). Of these, 594 respondents (79.9\%) participated in the one-year follow-up assessment (T1).

\section{Measures \\ Dependent variables}

The dependent variables used in this study are severity of depression and anxiety at baseline and one-year follow-up, measured by the 30-item Inventory of Depressive Symptomatology (Self-Report; IDS-SR) [20] and the 21-item Beck Anxiety Inventory (BAI) [21], respectively.

\section{Independent variables}

All determinants used in this paper were addressed at T0.

Determinants of a poor clinical outcome Determinants of outcome are classified according to Andersen's behavioral model [22,23], and include: 1) predisposing factors such as socio-demographic characteristics; 2) factors that enable the use of services such as income; and 3) factors that determine the need for care.

Predisposing factors: Information was gathered concerning socio-demographic characteristics such as age, gender, education level, country of birth, marital status and household composition. Social support was addressed by the number of family members, friends and acquaintances (adults only, household members excluded) with whom the respondent reported to be in regular and important contact. The De Jong-Gierveld Loneliness Scale [24] measures the amount of loneliness a respondent experiences by citing 11 statements such as 'I often feel rejected', which can be rated on a 3-point Likert scale.

Enabling factors: The income level and employment status of the respondent were ascertained during the interview.

Need for care: Two types of need for care were distinguished: a subjective and an objective need for care. A subjective need for mental health care is perceived by the patient and was ascertained by the Perceived Need for Care Questionnaire (PNCQ) [25]. The PNCQ is a fully structured interview that assesses the patient's perception of the presence of a mental problem, the perceived need for care and the patient's utilization of health care services. This translates as whether the patient consulted a GP, specialist, company doctor, social worker, psychologist, psychiatrist, psychotherapist or mental health institution for a mental problem. Patients who confirmed contact with at least one health care provider about a mental health problem were considered 'treated'. Patients who did not, were considered 'untreated'. 


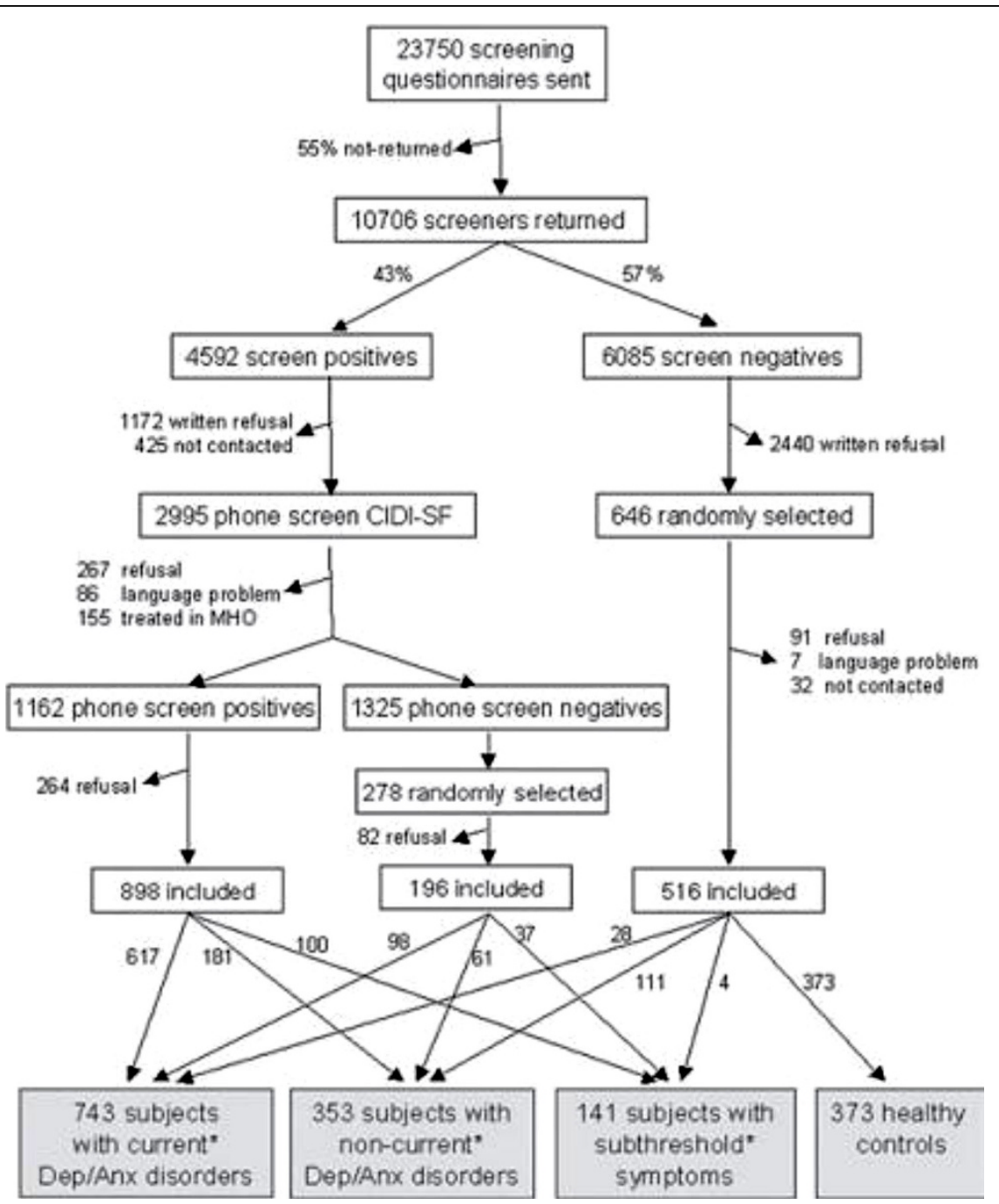

Figure 1 Recruitment flow of NESDA-respondents in the primary care sample. ${ }^{*}$ Current $=$ presence during the last six month; non-current $=$ presence before the last six months; subthreshold symptoms are defined as screen-postives of having a minor depression according to the CIDIinterview.

Patients' self-reported perceived need for care, was assessed for six types of care: information, medication, counseling, practical support, skills training and referral to a mental health care specialist. For each domain, respondents indicated if care was received (met need) and, if not, if care was wanted (unmet need) or not (no need). The PNCQ has shown acceptable reliability and validity for use in a community sample [25]. Although the Dutch version of the PNCQ has not specifically been validated, a study comparing PNCQ data from an Australian and a Dutch sample of primary care patients with anxiety and/or depression, showed many similarities between the given answers [26].

By means of the PNCQ, three patient groups with a DSM-IV diagnosis of anxiety or depression were distinguished, based on various reasons for not receiving treatment: 1) untreated patients who did not perceive themselves as having a mental problem; 2) untreated patients who perceived themselves as having a mental problem, but who did not report any need for care; and 3) untreated patients who perceived themselves as having a mental problem and expressed a need for care. These three groups will be compared with 4) patients with a DSM-IV diagnosis who received treatment.

An objective or clinical need for care is indicated by symptom severity (measured by the IDS and BAI), the presence of a comorbid anxiety or depressive disorder, a single or a recurrent disorder in case of a depression, and the recency of the experienced symptoms (measured by the CIDI). When multiple anxiety and/or depressive disorders where diagnosed, the symptom duration of the less recent disorder was used. To create an index of 
somatic health, an inventory was constructed to assess the number of chronic somatic diseases for which medical treatment was received.

\section{Statistical analysis}

Firstly, we explored potential differences between completers and non-completers of the one-year follow-up assessment in NESDA, by using $\chi^{2}$ analyses (for categorical variables) and t-tests (for continuous variables).

Secondly, we examined the one-year course of anxiety and depression in untreated and treated patients separately by performing multilevel repeated measures ANCOVA's, using baseline and one-year follow-up scale scores of symptom severity in anxiety (BAI) and depression (IDS), respectively. The previous mentioned predisposing, enabling and need for care factors were added as covariates. To take into account the possible influence of GPs on the patients' treatment receipt, multilevel models with random intercepts were used, consisting of patients (level 1) nested within GPs (level 2). Specifically, in the multilevel repeated measures ANCOVA's, chi-squared tests were performed to compare the regression weights of the course of anxiety and depression in each patient group, controlling for the influence of different predisposing, enabling and need for care factors. Multilevel modeling takes into account all available baseline and one-year follow-up data from both completers and noncompleters, and imputes missing data from respondents who completed only the baseline assessment.

Furthermore, to determine the characteristics of clinical outcome at T1, multilevel univariate linear regression analyses with random intercepts were performed for anxiety (using the BAI scale scores at T1) and depression (using the IDS scale scores at T1) separately. Additionally, a multilevel multivariate linear regression model with random intercepts was used to determine which of the previously mentioned characteristics predicted clinical outcome when all variables were considered simultaneously. Baseline scale scores of the BAI and IDS were added to control for baseline symptom severity. Since these analyses aimed at predicting clinical outcome at $\mathrm{T} 1$, we were unable to impute missing data. Therefore, only respondents who completed the one-year follow-up assessment were considered in these analyses. The multilevel repeated measures ANCOVA's were carried out in MLwiN 2.02; for all other analyses, STATA 10.0 was used.

\section{Results}

\section{Characteristics of the study sample}

The sample contains 594 respondents, and $71.2 \%$ are women $(\mathrm{N}=423)$. At baseline, respondents were on average 45.7 years old (sd. 11.9 years), with the youngest participant being 18 years of age and the oldest 65 .
Participants had an average of 12.0 years (sd. 3.4 years) of education, ranging from 5 to 18 years. The majority of patients had a six-month diagnosis for an anxiety disorder $(79.1 \% ; \mathrm{N}=470) ; 56.2 \%(\mathrm{~N}=334)$ were diagnosed with a depression, and $35.4 \%(\mathrm{~N}=210)$ of patients suffered from both.

Compared to baseline assessment, 20.1\% ( $\mathrm{N}=149)$ of the respondents were lost to attrition at one-year follow-up. Compared to non-completers, completers were older (45.7 vs. 41.6; $\mathrm{p}<.01$ ), had a higher level of education $(\mathrm{p}<.01)$, experienced more loneliness $(5.1 \mathrm{vs.}$ $3.0 ; \mathrm{p}<.001)$ and social support (6.7 vs. $5.6 ; \mathrm{p}<.05)$, and reported less severe symptoms of anxiety (15.2 vs. $19.4 ; \mathrm{p}<.001)$ and depression (26.5 vs. $29.8 ; \mathrm{p}<.01)$. A description of the untreated and treated patients is given in Table 1 .

\section{The course of depression and anxiety}

Figures 2 and 3 show the results of the multilevel repeated measures ANCOVA's, examining the course of anxiety measured by the BAI, and the course of depression assessed by the IDS, at T0 and T1. All patients suffered from a CIDI-diagnosis of anxiety or depression, respectively. Data of respondents who completed only the baseline assessment were also taken into account.

The course of depression differs between untreated patients without a self-perceived mental problem compared to untreated patients with an unmet need for care $\left(\chi^{2}=6.35, \mathrm{p}<.05\right)$ and treated patients $\left(\chi^{2}=22.16, \mathrm{p}<\right.$ $.001)$. Also, untreated patients without a need for care show a different one-year course than untreated patients with an unmet need for care $\left(\chi^{2}=4.25, \mathrm{p}<.05\right)$ and treated patients $\left(\chi^{2}=16.08, \mathrm{p}<.001\right)$.

In anxiety, the one-year course only differs between untreated patient without a self-perceived mental problem and untreated patients without a need for care $\left(\chi^{2}=3.85\right.$, $\mathrm{p}<.05)$.

\section{Determinants of a poor clinical outcome}

Next, risk factors of a poor clinical outcome were examined by multilevel univariate and multivariate linear regression analyses. The results are shown in Table 2 (anxiety) and 3 (depression).

At T1, symptom severity in anxiety was negatively associated with a higher education level $(\beta=-6.09, \mathrm{SE}=1.68$, $\mathrm{p}<.001)$, social support $(\beta=-.21, \mathrm{SE}=.09, \mathrm{p}<.05)$, a higher income $(\beta=-2.86, \mathrm{SE}=.92, \mathrm{p}<.01)$, perceiving no mental problem $(\beta=-7.40, \mathrm{SE}=1.34, \mathrm{p}<.001)$ or perceiving no need for care $(\beta=-3.47, \mathrm{SE}=1.36, \mathrm{p}<$ .05). Positive associations were found between more symptom severity in anxiety and loneliness $(\beta=.40, \mathrm{SE}=$ $.12, \mathrm{p}<.01)$, being unemployed $(\beta=3.49, \mathrm{SE}=.91$, $\mathrm{p}<.001$ ), suffering from a comorbid depressive disorder $(\beta=4.32, \mathrm{SE}=.87, \mathrm{p}<.001)$ or from somatic diseases 
Table 1 Differences between untreated and treated patients at TO ( $N=594)$

\begin{tabular}{|c|c|c|c|c|c|c|c|c|}
\hline & \multicolumn{2}{|c|}{$\begin{array}{l}\text { 1. Untreated - unperceived } \\
\text { problem }\end{array}$} & \multicolumn{2}{|c|}{$\begin{array}{l}\text { 2. Untreated - } \\
\text { unperceived need }\end{array}$} & \multicolumn{2}{|c|}{$\begin{array}{l}\text { 3. Untreated - unmet } \\
\text { perceived need }\end{array}$} & \multicolumn{2}{|c|}{ 4. Treated } \\
\hline & $\mathrm{M} \pm \mathrm{SD} / \%$ & $\mathrm{~N}$ & $\mathrm{M} \pm \mathrm{SD} / \%$ & $\mathrm{~N}$ & $\mathrm{M} \pm \mathrm{SD} / \%$ & $\mathrm{~N}$ & $\mathrm{M} \pm \mathrm{SD} / \%$ & $\mathrm{~N}$ \\
\hline \multicolumn{9}{|l|}{ Predisposing characteristics } \\
\hline Male gender (\%) & 34.8 & 24 & 30.0 & 21 & 29.0 & 36 & 27.2 & 90 \\
\hline \multicolumn{9}{|l|}{ Age $(\%)$} \\
\hline 1. $18-35$ & 21.7 & 15 & 12.9 & 9 & 22.6 & 28 & 26.6 & 88 \\
\hline 2. $36-50$ & 27.5 & 19 & 34.3 & 24 & 32.3 & 40 & 36.3 & 120 \\
\hline 3. $51-65$ & 50.7 & 35 & 52.9 & 37 & 45.2 & 56 & 37.2 & 123 \\
\hline \multicolumn{9}{|l|}{ Education (\%) } \\
\hline 1. Basic & 5.8 & 4 & 7.1 & 5 & 13.7 & 17 & 5.7 & 19 \\
\hline 2. Intermediate & 60.9 & 42 & 62.9 & 44 & 53.2 & 66 & 59.5 & 197 \\
\hline 3. High & 33.3 & 23 & 30.0 & 21 & 33.1 & 41 & 34.7 & 115 \\
\hline Born outside the Netherlands $(\%)^{\mathrm{a} *}$ & 13.0 & 9 & $5.7^{3}$ & 4 & $18.6^{2,4}$ & 23 & $9.4^{3}$ & 31 \\
\hline \multicolumn{9}{|l|}{ Marital status (\%) } \\
\hline Never married & 40.6 & 28 & 32.9 & 23 & 36.3 & 45 & 42.0 & 139 \\
\hline Currently married & 42.0 & 29 & 45.7 & 32 & 46.8 & 58 & 40.2 & 133 \\
\hline Formerly married & 17.4 & 12 & 21.4 & 15 & 16.9 & 21 & 17.8 & 59 \\
\hline Household composition - alone (\%) & 33.3 & 23 & 37.1 & 26 & 33.9 & 42 & 33.8 & 112 \\
\hline Loneliness $(\mathrm{M} \pm \mathrm{SD} \text {; range } 0-10)^{\mathrm{b}_{* * *}}$ & $3.5 \pm 3.2^{3,4}$ & 68 & $4.6 \pm 3.7^{3}$ & 69 & $6.2 \pm 3.7^{1,2}$ & 123 & $5.3 \pm 3.8^{1}$ & 328 \\
\hline Social support $(\mathrm{M} \pm \mathrm{SD} \text {; range } 0-22)^{C_{* *}}$ & $8.4 \pm 5.6^{3}$ & 69 & $7.3 \pm 5.2$ & 70 & $5.5 \pm 4.3^{1}$ & 124 & $6.6 \pm 5.1$ & 331 \\
\hline \multicolumn{9}{|l|}{ Enabling factors } \\
\hline \multicolumn{9}{|l|}{ Income in euro's p.m.(\%) } \\
\hline$<€ 2.400,-$ & 60.9 & 42 & 62.7 & 42 & 68.9 & 84 & 63.0 & 208 \\
\hline$>€ 2.400$ & 39.1 & 27 & 37.3 & 25 & 40.3 & 50 & 30.8 & 102 \\
\hline Employment status - unemployed (\%) & 29.0 & 20 & 38.6 & 27 & 40.3 & 50 & 30.8 & 102 \\
\hline \multicolumn{9}{|l|}{ Need factors } \\
\hline \multicolumn{9}{|l|}{ Type of disorder } \\
\hline Major depression single $(\%)^{\mathrm{d}} * * *$ & $7.3^{3,4}$ & 5 & $8.6^{3,4}$ & 6 & $21.8^{1,2}$ & 27 & $28.7^{1,2}$ & 95 \\
\hline Major depression recurrent $(\%)^{\mathrm{e} * * *}$ & $5.8^{2,3,4}$ & 4 & $28.6^{1}$ & 20 & $31.5^{1}$ & 39 & $37.5^{1}$ & 124 \\
\hline Dysthemia $(\%)^{f * *}$ & $4.4^{3,4}$ & 3 & $7.1^{3,4}$ & 5 & $17.7^{1,2}$ & 22 & $17.8^{1,2}$ & 59 \\
\hline General anxiety disorder (GAD) $(\%)^{g} * *$ & $10.1^{3,4}$ & 7 & $14.3^{4}$ & 10 & $25.8^{1}$ & 32 & $29.3^{1,2}$ & 97 \\
\hline Social phobia $(\%)^{\mathrm{h} *}$ & 39.1 & 27 & $24.3^{3,4}$ & 17 & $46.0^{2}$ & 57 & $37.2^{2}$ & 123 \\
\hline Panic without agoraphobia $(\%)^{1 * *}$ & 10.2 & 7 & $27.1^{3,4}$ & 19 & $12.9^{2}$ & 16 & $11.8^{2}$ & 39 \\
\hline Panic with agoraphobia (\%) & 15.9 & 11 & 15.7 & 11 & 16.1 & 20 & 24.8 & 82 \\
\hline Agoraphobia without panic (\%) & 21.7 & 15 & 17.1 & 12 & 16.9 & 21 & 11.2 & 37 \\
\hline At least one depressive disorder $(\%)^{j * * *}$ & $14.5^{2,3,4}$ & 10 & $38.6^{1,3,4}$ & 27 & $56.5^{1,2,4}$ & 70 & $68.6^{1,2,3}$ & 227 \\
\hline Comorbid anxiety and depressive disorder $(\%)^{k_{* * *}}$ & $1.5^{2,3,4}$ & 1 & $20.0^{1,3,4}$ & 14 & $37.9^{1,2}$ & 47 & $44.7^{1,2}$ & 148 \\
\hline \multicolumn{9}{|l|}{ Recency (\%) } \\
\hline$<6$ months & 46.4 & 32 & 41.4 & 29 & 51.6 & 64 & 56.5 & 187 \\
\hline $6-12$ months & 4.4 & 3 & 4.3 & 3 & 6.5 & 8 & 6.0 & 20 \\
\hline$>12$ months & 49.3 & 34 & 54.3 & 38 & 41.9 & 52 & 37.5 & 124 \\
\hline Number of somatic diseases $(M \pm S D)$ & $.8 \pm 1.0$ & 69 & $.5 \pm 1.0$ & 70 & $.9 \pm 1.1$ & 124 & $.7 \pm 1.1$ & 331 \\
\hline Severity anxiety $(B A I)$ TO $(M \pm S D \text {; range } 0-63)^{1 * * *}$ & $8.2 \pm 5.2^{2,3,4}$ & 69 & $12.4 \pm 8.0^{1,3,4}$ & 70 & $16.5 \pm 9.3^{1,2}$ & 124 & $16.7 \pm 9.8^{1,2}$ & 331 \\
\hline Severity of depression (IDS) $(M \pm S D \text {; range } 0-84)^{m_{* * *}}$ & $15.7 \pm 7.3^{2,3,4}$ & 68 & $22.0 \pm 8.4^{1,3,4}$ & 70 & $28.6 \pm 9.5^{1,2}$ & 124 & $29.0 \pm 11.4^{1,2}$ & 330 \\
\hline
\end{tabular}

${ }^{*} p<.05{ }^{* *} p<.01{ }^{* * *} p<.001$.

$1,2,3,4$ numbers refer to groups who differ significantly from each other.

${ }^{\mathrm{a}} \chi^{2}(3)=10.14, \mathrm{p}=.017$.

${ }^{\mathrm{b}} \mathrm{F}(3,584)=8.64, \mathrm{p}=.000$.

${ }^{c} \mathrm{~F}(3,590)=5.03, \mathrm{p}=.002$.

${ }^{\mathrm{d}} \chi^{2}(3)=24.41, \mathrm{p}=.000$.

e $\chi^{2}(3)=26.87, p=.000$.

${ }^{\mathrm{f}} \chi^{2}(3)=12.34, \mathrm{p}=.006$

${ }^{g} \chi^{2}(3)=15.84, p=.001$.

${ }^{\mathrm{h}} \chi^{2}(3)=9.07, \mathrm{p}=.028$

${ }^{1} \chi^{2}(3)=12.58, p=.006$.

${ }^{\mathrm{j}} \chi^{2}(3)=78.22, \mathrm{p}=.000$.

${ }^{k} \chi^{2}(3)=54.96, p=.000$.

${ }^{\prime} \mathrm{F}(3,590)=20.02, \mathrm{p}=.000$.

${ }^{m} \mathrm{~F}(3,588)=38.03, p=.000$. 


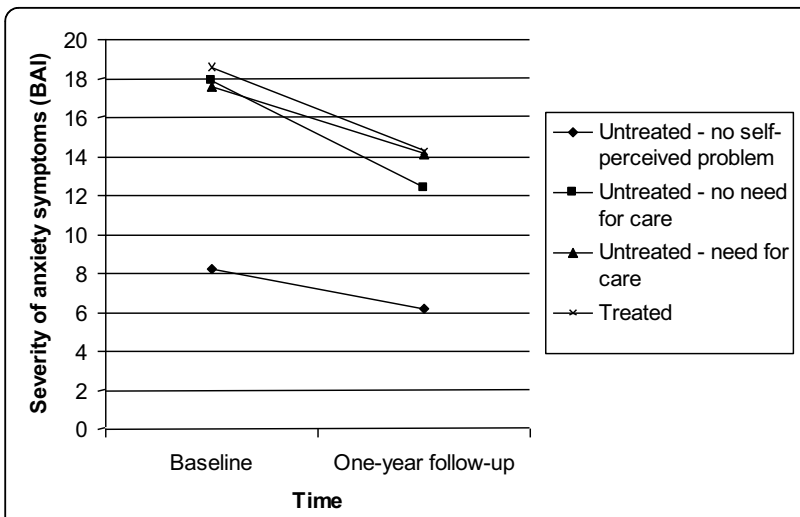

Figure 2 The course of anxiety in patients with a CIDIdiagnosis of an anxiety disorder at T0, in the treatment/nontreatment groups ( $\mathbf{N}=\mathbf{4 2 2}$ ) (range: $\mathbf{0 - 6 3}$ ). Data of respondents who did not complete the one-year follow-up assessment were also included in the multilevel repeated measures ANCOVA.

$(\beta=1.30, \mathrm{SE}=.44, \mathrm{p}<.01)$ and greater symptom severity at baseline $(\beta=.59, \mathrm{SE}=.04, \mathrm{p}<.001)$. The same associations were found in depression (see Table 3). Additionally, persons with a depressive disorder who were born outside the Netherlands were at risk of a higher symptom severity at one-year follow-up than respondents born in the Netherlands $(\beta=4.30, \mathrm{SE}=1.97, \mathrm{p}<.05)$.

Furthermore, multilevel multivariate linear regression analyses were performed (see last columns of Table 2 and 3 ). When all variables were considered simultaneously, only baseline symptom severity predicted clinical outcome at one-year follow-up in respondents with an anxiety disorder $(\beta=.54, \mathrm{SE}=.04, \mathrm{p}<.001)$. In depression, besides baseline symptom severity $(\beta=.53$, $\mathrm{SE}=.05, \mathrm{p}<.001)$, a higher symptom severity at oneyear follow-up was also predicted by more loneliness

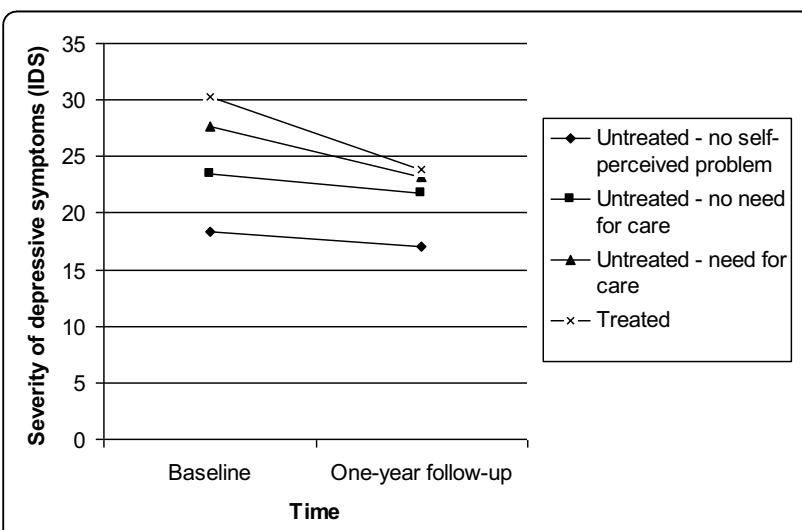

Figure 3 The course of depression in patients with a CIDIdiagnosis of a depressive disorder at T0, in the treatment/nontreatment groups ( $\mathrm{N}=\mathbf{5 7 3}$ ) (range: $\mathbf{0 - 8 4}$ ). Data of respondents who did not complete the one-year follow-up assessment were also included in the multilevel repeated measures ANCOVA. $(\beta=.39, \mathrm{SE}=.16, \mathrm{p}<.05)$ and having a comorbid anxiety disorder $(\beta=2.95, \mathrm{SE}=1.18, \mathrm{p}<.05)$.

\section{Discussion}

Our results revealed that all groups of untreated and treated patients showed a modest decrease in anxiety and depressive symptoms after one year. Although untreated patients with a perceived need for care and treated patients showed a more rapid symptom decrease, rank order in symptom severity was maintained: they experienced more severe symptoms at $\mathrm{T} 0$ and $\mathrm{T} 1$ than untreated patients without a perceived mental problem (in anxiety or depression) or without a perceived need for care (in depression only). This association between initial severity and symptom decline at follow-up has been noted previously [27]. Furthermore, our findings confirm previous results from the NEMESIS study [28], which concluded that more intensive treatment is associated with a poorer outcome at one-year follow-up. This is clinically a logical finding as it points at confounding by indication.

Initially, we found that a poor clinical outcome in depression and anxiety was determined by a lower education level, increased loneliness, less social support, a lower income, unemployment, perceiving a need for care, the presence of a comorbid anxiety or depressive disorder, somatic diseases and increased baseline symptom severity. In depression, higher symptom severity at oneyear follow-up was also predicted by being born outside the Netherlands.

Despite these findings from univariate analyses, however, only increased loneliness and the presence of a comorbid anxiety disorder maintained their significance in predicting a poor outcome in depression when controlled for baseline symptom severity. Apparently, most differences in predisposing, enabling and need factors were attributable to initial symptom severity. In anxiety, baseline symptom severity appeared to be the only predictor of a poor outcome at follow-up in the multivariate analysis. Indeed, other community studies likewise showed that symptom severity at baseline was (one of) the most prominent determinant(s) of poor outcome [27,29-31]. However, to our knowledge, the finding that increased loneliness predicts a poor outcome in depression, independently of baseline symptom severity, has not been shown before in a community sample.

Younger age appeared to be a mutually independent predictor of poor outcome in the study of Spijker et al. [29]. Differences in study design may account for the fact that this finding was not replicated by our study: Spijker et al. [29] defined severity as a severe disorder with psychotic features. Moreover, perhaps our study population differed from the population they studied: respondents who completed the one-year follow-up in the NESDA-study were, 
Table 2 Potential risk factors of a poor outcome in anxiety at T1: multilevel univariate and multivariate linear regression analyses

\begin{tabular}{|c|c|c|c|c|c|c|}
\hline & \multicolumn{3}{|r|}{ Univariate } & \multicolumn{3}{|r|}{ Multivariate } \\
\hline & $\beta$ & SE & Variance at GP-level (SE) & $\beta$ & SE & Variance at GP-level (SE) \\
\hline \multicolumn{7}{|l|}{ Predisposing characteristics } \\
\hline Male gender & -.97 & .98 & $.08(2.21)$ & .20 & .79 & \\
\hline \multicolumn{7}{|l|}{ Age } \\
\hline 1. $18-35$ & ref & & & ref & & \\
\hline 2. $36-50$ & 1.94 & 1.20 & & 1.29 & 1.05 & \\
\hline 3. $51-65$ & 1.56 & 1.15 & $.18(2.23)$ & 1.48 & 1.11 & \\
\hline \multicolumn{7}{|l|}{ Education } \\
\hline 1. Basic & ref & & & ref & & \\
\hline 2. Intermediate & -2.87 & 1.59 & & -.08 & 1.31 & \\
\hline 3. High & $-6.09 * * *$ & 1.68 & $1.57(2.51)$ & -1.59 & 1.43 & \\
\hline Born outside the Netherlands & 2.25 & 1.42 & $.00(.01)$ & .60 & 1.14 & \\
\hline \multicolumn{7}{|l|}{ Marital status } \\
\hline Never married & -.72 & .99 & & .35 & 1.06 & \\
\hline Currently married & ref & & & ref & & \\
\hline Formerly married & -.11 & 1.25 & $.33(2.29)$ & -1.28 & 1.06 & \\
\hline Household composition - alone & .37 & .96 & $.08(2.24)$ & .09 & .97 & \\
\hline Loneliness (range 0-10) & $.40^{* *}$ & .12 & $.00(.00)$ & -.02 & .10 & \\
\hline Social support (range 0-22) & $-.21^{*}$ & .09 & $.00(.00)$ & -.05 & .07 & \\
\hline \multicolumn{7}{|l|}{ Enabling factors } \\
\hline \multicolumn{7}{|l|}{ Income in euro's p.m. } \\
\hline$<€ 2.400$ & ref & & & ref & & \\
\hline$>€ 2.400$ & $-2.86^{* *}$ & .92 & $.00(.00)$ & -1.48 & .86 & \\
\hline Employment status - unemployed & $3.49^{* * *}$ & .91 & $.00(.01)$ & .42 & .81 & \\
\hline \multicolumn{7}{|l|}{ Need factors } \\
\hline \multicolumn{7}{|l|}{ Perceived need for care } \\
\hline 1. No need for care - no perceived mental Problem & $-7.40^{* * *}$ & 1.34 & & -1.78 & 1.23 & \\
\hline 2. No need for care - a perceived mental problem & $-3.47^{* *}$ & 1.36 & & -.19 & 1.18 & \\
\hline 3. Need for care - unmet & .40 & 1.09 & $.16(2.11)$ & .64 & .93 & \\
\hline 4. Need for care - met & ref & & & ref & & \\
\hline \multicolumn{7}{|l|}{ Recency } \\
\hline$<6$ months & ref & & & ref & & \\
\hline $6-12$ months & 3.08 & 2.02 & & 2.85 & 1.63 & \\
\hline$>12$ months & -1.08 & .91 & $.00(.00)$ & -.04 & .76 & \\
\hline Comorbid anxiety and depressive disorder & $4.31^{* * *}$ & .87 & $.00(.00)$ & .16 & .84 & \\
\hline Number of somatic diseases & $1.30^{* *}$ & .44 & $.01(1.96)$ & .57 & .39 & \\
\hline Severity of anxiety T0 (BAl; range $0-63$ ) & $.59^{* * *}$ & .04 & $1.47(1.68)$ & $.54^{* * *}$ & .04 & \\
\hline & & & & & & $1.54(1.71)$ \\
\hline
\end{tabular}

${ }^{*} p<.05 * *<.01 * * p<.001$.

for instance, older and lonelier than non-completers, which could have affected our results.

\section{Strengths and weaknesses of the study}

An important strength of the present study concerns the inclusion and comprehensive measurement of perceived need for care for a mental disorder, using the PNCQ. Furthermore, we made use of a large sample. However, in considering the results reported here, some limitations must be noted.
Firstly, our study employed observational data. No conclusions about a causal relationship between care utilization and clinical outcome can therefore be drawn. Our data are not suitable for determining the effectiveness of treatments. Moreover, our study suffers from selective attrition. Most important is that respondents who completed the one-year follow-up experienced less severe depressive and anxiety symptoms at baseline than noncompleters, while severity is our outcome measure. We were able to include respondents who only completed the 
Table 3 Potential risk factors of a poor outcome in depression at T1: multilevel univariate and multivariate linear regression analyses

\begin{tabular}{|c|c|c|c|c|c|c|}
\hline & \multicolumn{3}{|r|}{ Univariate } & \multicolumn{3}{|r|}{ Multivariate } \\
\hline & $\beta$ & SE & Variance at GP-level (SE) & $\beta$ & SE & Variance at GP-level (SE) \\
\hline \multicolumn{7}{|l|}{ Predisposing characteristics } \\
\hline Male gender & -.87 & 1.46 & $.00(.00)$ & -.61 & 1.17 & \\
\hline \multicolumn{7}{|l|}{ Age } \\
\hline 1. $18-35$ & ref & & & ref & & \\
\hline 2. $36-50$ & 1.08 & 1.74 & & -1.61 & 1.54 & \\
\hline 3. $51-65$ & 4.44 & 1.70 & $.00(.00)$ & 2.07 & 1.64 & \\
\hline \multicolumn{7}{|l|}{ Education } \\
\hline 1. Basic & ref & & & ref & & \\
\hline 2. Intermediate & $-5.65^{*}$ & 2.53 & & -1.93 & 2.07 & \\
\hline 3. High & $-8.16^{* *}$ & 2.63 & $.00(.00)$ & -3.23 & 2.24 & \\
\hline Born outside the Netherlands & $4.30^{*}$ & 1.97 & $.00(.00)$ & 1.57 & 1.60 & \\
\hline \multicolumn{7}{|l|}{ Marital status } \\
\hline Never married & -1.70 & 1.46 & & .08 & 1.59 & \\
\hline Currently married & ref & & & ref & & \\
\hline Formerly married & -.27 & 1.83 & $.00(.00)$ & -1.69 & 1.62 & \\
\hline Household composition - alone & .11 & 1.38 & $.00(.00)$ & -.79 & 1.44 & \\
\hline Loneliness (range 0-10) & $.89^{* * *}$ & .17 & $.00(.00)$ & $.39^{*}$ & .16 & \\
\hline Social support (range 0-22) & $-.36^{* *}$ & .14 & $1.11(4.83)$ & -.02 & .12 & \\
\hline \multicolumn{7}{|l|}{ Enabling factors } \\
\hline \multicolumn{7}{|l|}{ Income in euro's p.m. } \\
\hline$<€ 2.400$ & ref & & & ref & & \\
\hline$>€ 2.400$ & $-2.79^{*}$ & 1.38 & $.00(.00)$ & -1.16 & 1.31 & \\
\hline Employment status - unemployed & $4.77^{* * *}$ & 1.34 & $.00(.00)$ & .26 & 1.18 & \\
\hline \multicolumn{7}{|l|}{ Need factors } \\
\hline \multicolumn{7}{|l|}{ Perceived need for care } \\
\hline 1. No need for care - no perceived mental problem & $-8.00^{*}$ & 3.97 & & 2.71 & 3.20 & \\
\hline 2. No need for care - a perceived mental problem & -1.43 & 2.47 & & 2.00 & 2.07 & \\
\hline 3. Need for care - unmet & 3.05 & 1.62 & & 1.55 & 1.31 & \\
\hline 4. Need for care - met & ref & & $.00(.00)$ & ref & & \\
\hline Recurrent depressive disorder & -1.52 & 1.32 & $.00(.00)$ & .79 & 1.07 & \\
\hline \multicolumn{7}{|l|}{ Recency } \\
\hline$<6$ months & ref & & & ref & & \\
\hline $6-12$ months & 1.01 & 2.98 & & -.68 & 2.34 & \\
\hline$>12$ months & -1.54 & 1.46 & $.00(.00)$ & -.72 & 1.18 & \\
\hline Comorbid anxiety and depressive disorder & $8.23^{* * *}$ & 1.29 & $.00(.01)$ & $2.95^{*}$ & 1.18 & \\
\hline Number of somatic diseases & $1.78^{* *}$ & .54 & $.00(.00)$ & .23 & .49 & \\
\hline \multirow[t]{2}{*}{ Severity of depression T0 (IDS; range 0-84) } & $.63^{* * *}$ & .05 & $3.16(3.71)$ & $.53^{* * *}$ & .05 & \\
\hline & & & & & & $2.59(3.29)$ \\
\hline
\end{tabular}

${ }^{*} p<.05 * * p<.01 * * p<.001$

baseline assessment in the multilevel analyses examining the course of anxiety and depression. However, since we aimed at predicting poor clinical outcome at T1 in the following analyses, imputation of missing data was impossible.

A final limitation concerns the generalizability of our findings. Since respondents were recruited from the vicinity of three large cities, people from these highly urbanized regions were overrepresented in our sample. Also, two patient groups are underrepresented in the NESDA study: those who rarely or never visited their general practitioner and therefore could not be approached to take part in this study during the four months of recruitment, and patients who were not fluent in Dutch.

\section{Clinical implications}

An important implication of our study is the necessity to differentiate between several groups of untreated 
patients. Rost's [16] finding that untreated depression has a poor prognosis should be limited to those people suffering from depression (or anxiety disorder) with unmet needs for care. Our results imply that half of the respondents in the untreated group, those without a self-perceived mental problem or treatment need, make an adequate estimation of their need for care: they reported less severe symptoms at baseline, and had a mostly favorable clinical outcome at one-year follow-up. Patients with a perceived need for care (which was or was not met) had a poorer outcome, and already suffered from a severe depression or anxiety disorder at baseline. However, untreated patients with a depressive disorder who expressed a need for care showed the least improvement, lonely patients and those with a comorbid anxiety disorder in particular. This is the target group Rost [16] is aiming at. Therefore, it is important that primary care workers pay attention to a patient's need for care, Especially, patients with a low social-economical status and little support with some signs of depression or anxiety might be systematically prompted about a possible need for care [29].

The course of anxiety and depression did not differ significantly between untreated patients with a perceived need for care, and those who received treatment. This raises the question whether treatment could have improved clinical outcome in those untreated patients with a need for care. However, these results must be interpreted with caution, as mentioned before. First of all, patients in the treated and non-treated groups were not randomly assigned to their conditions. Instead, distinctions were based on self-selection. Therefore, other factors determining important differences between these groups could account for the absence of differences in clinical outcome. In addition, it may well be the case that without receiving treatment, the now treated persons would have had much higher symptom levels or a poorer course. Apparently, receipt of and need for care are not independent of symptom severity in predicting the outcome of depression and anxiety. Similarly, utilization of professional care appeared to be the strongest predictor of poor outcome in the NEMESIS study, causing symptom severity to lose its significance in the prediction model [29]. It is important to realize that our observational cohort results for treated and non-treated persons cannot be directly interpreted as providing evidence for the effectiveness of treatment. Therefore, it would be of interest to investigate in more detail the differences between patients who do receive treatment, and those who do not although they perceive a need for care, in terms of personality characteristics, a prior history of anxiety and depression etc. Furthermore, this study considers patients to be treated when they confirmed contact with one or more (mental health) care providers for their anxiety or depressive disorder. However, we do not know how intensively they were treated. For instance, it is unknown whether they visited their GP only once, or attended frequently for their mental problem. Clearly, greater understanding is needed in this area.

\section{Conclusion}

Our study identified a considerable number of patients with a current anxiety or depressive disorder and an unmet need for care, who showed the poorest one-year outcome compared to untreated patients without a need for care. Therefore, primary care workers should perhaps pay more attention to these patients, look actively among risk groups (low SES, low social support) for possible cases, explore their possible needs for care and support them in making an informed decision on whether or not to seek further treatment

\section{Acknowledgements}

This paper was supported by a grant from 'Fonds Psychische Gezondheid' (mental health fund; grant number 20076240). The infrastructure for the NESDA study (http://www.nesda.nl) is funded through the Geestkracht program of the Netherlands Organization for Health Research and Development (ZonMw, grant number 10-000-1002) and is supported by participating universities and mental health care organizations (VU University Medical Center, GGZ inGeest, Arkin, Leiden University Medical Center, GGZ Rivierduinen, University Medical Center Groningen, Lentis, GGZ Friesland, GGZ Drenthe, Scientific Institute for Quality of Healthcare (IQ healthcare), Netherlands Institute for Health Services Research (NIVEL) and Netherlands Institute of Mental Health and Addiction (Trimbos).

The authors would like to thank Peter Spreeuwenberg (affiliated with NIVEL) for his statistical advice.

\section{Author details}

${ }^{1}$ Netherlands Institute for Health Services Research, Utrecht, the Netherlands. ${ }^{2}$ Department of Clinical Psychology, VU University, Amsterdam, the Netherlands. ${ }^{3}$ Department of General Practice, VU University Medical Centre, Amsterdam, the Netherlands. ${ }^{4}$ Department of Psychiatry/EMGO Institute, VU University Medical Centre, Amsterdam, the Netherlands. ${ }^{5}$ Department of Psychiatry, Leiden University Medical Center, Leiden, the Netherlands. ${ }^{6}$ Department of Psychiatry, University Medical Centre Groningen, University of Groningen, Groningen, the Netherlands.

\section{Authors' contributions}

IVB and PV participated in the design of the study, performed and interpreted the statistical analyses and were involved in drafting the manuscript. PC and HM have critically revised the manuscript. BP is the principal investigator of the NESDA study, and participated in the design of the study and revising the manuscript. All authors read and approved the final manuscript.

\section{Competing interests}

The authors declare that they have no competing interests.

Received: 27 March 2010 Accepted: 20 October 2010

Published: 20 October 2010

\section{References}

1. Moitabai R: Unmet need for treatment of major depression in the United States. Psychiatric Services 2009, 60:297-305.

2. Wang PS, Aguilar-Gaxiola S, Alonso J, Angermeyer MC, Borges G, Bromet EJ, et al: Use of mental health services for anxiety, mood, and substance disorders in 17 countries in the WHO world mental health surveys. Lancet 2007, 370:841-850. 
3. Alonso J, Angermeyer MC, Bernert S, Bruffaerts R, Brugha TS, Bryson H, et al: Use of mental health services in Europe: results from the European Study of the Epidemiology of Mental Disorders (ESEMeD) project. Acta Psychiatrica Scandinavia 2004, 47-54.

4. WHO World Mental Health Survey Consortium: Prevalence, severity and unmet need for treatment of mental disorders in the world health organization world mental health surveys. JAMA 2004, 291:2581-2590.

5. Bijl RV, Graaf Rd, Hiripi E, Kessler RC, Kohn R, Offord RD, et al: The prevalence of treated and untreated mental disorders in five countries. Health Aff 2003, 22:122-133.

6. Andrews G, Issakidis C, Carter G: Shortfall in mental health service utilisation. Br J Psychiatry 2001, 179:417-425

7. Kessler RC, Berglund PA, Bruce ML, Koch R, Laska EM, Leaf PJ, et al: The prevalence and correlates of untreated serious mental illness. Health Serv Res 2001, 36:987-1007.

8. Bebbington $P$, Meltzer $H$, Brugha TS, Farrell M, Jenkins R, Ceresa $C$, et al: Unequal access and unmet need: neurotic disorders and the use of primary care services. Psychol Med 2000, 30:1359-1367.

9. Verhaak PFM, Prins MA, Spreeuwenberg P, Draisma S, Balkom AJLM, Bensing JM, Laurant MGH, van Marwijk HWJ, van der Meer $\mathrm{K}$, Penninx BWJH: Receiving treatment for common mental disorders. Gen Hosp Psychiatry 2009, 31:46-55.

10. Parslow RA, Jorm AF: Who uses mental health services in Australia? An analysis of data from the national survey of mental health and wellbeing. Aust NZ J Psychiat 2000, 34:997-1008.

11. Bland RC, Newman SC, Orn H: Help-seeking for psychiatric disorders. Can J Psychiatry 1997, 42:935-941.

12. Coyne JC, Klinkman MS, Gallo SM, Schwenk TL: Short term outcomes of detected and undetected depressed primary care patients and depressed psychiatric patients. Gen Hosp Psychiatry 1997, 19:333-343.

13. Van Beljouw IMJ, Verhaak PFM, Prins MA, Cuijpers P, Penninx BWJH, Bensing JM: Reasons and Determinants for Not Receiving Treatment for Common Mental Disorders. Psychiatr Serv 2010, 61:250-257.

14. Kessler RC, Berglund PA, Bruce ML, Koch R, Laska EM, Leaf PJ, et al: The prevalence and correlates of untreated serious mental illness. Health Serv Res 2001, 36:987-1007.

15. Sareen J, Cox BJ, Afifi TO, Clara I, Yu BN: Perceived need for mental health treatment in a nationally representative Canadian sample. Can J Psychiatry 2005, 50:643-651

16. Rost K, Zhang M, Fortney J, Smith J, Coyne JC, Smith GR: Persistently poor outcomes of undetected major depression in primary care. Gen Hosp Psychiatry 1998, 20:12-20.

17. Penninx BW, Beekman AT, Smit JH, Zitman FG, Nolen WA, Spinhoven P, et al: The Netherlands Study of Depression and Anxiety (NESDA): rationale, objectives and methods. Int J Methods Psychiatr Res 2008, 17:121-140.

18. Kessler RC, Barker PR, Colpe LJ, Epstein JF, Gfroerer JC, Hiripi E, et al: Screening for serious mental illness in the general population. Archives of General Psychiatry 2003, 60:184-189.

19. World Health Organization: Composite Interview Diagnostic Instrument (CIDI). World Health Organization 1990.

20. Rush AJ, Gullion CM, Basco MR, Jarrett RB, Trivedi MH: The Inventory of Depressive Symptomatology (IDS): psychometric properties. Psychological Medicine 1996, 26:477-486.

21. Beck AT, Epstein N, Brown G, Steer RA: An inventory for measuring clinical anxiety: psychometric properties. J Consult Clin Psychol 1988, 56:893-897.

22. Andersen R, Newman J: Societal and individual determinants of medical care utilization in the United States. Millbank Memory Fund Quarterly 1973, 51:95-124.

23. Andersen RM: Revisiting the behavioral model on acces to medical care: does it matter? Journal of Health and Social Behavior 1995, 36:1-10.

24. Jong-Gierveld J, Kamphuis F: The development of a Rasch-type loneliness scale. Applied Psychological Measurement 1985, 9:289-299.

25. Meadows G, Harvey C, Fossey E, Burgess P: Assessing perceived need for mental health care in a community survey: development of the Perceived Need for Care Questionnaire (PNCQ). Social Psychiatry and Psychiatric Epidemiology 2000, 35:427-435.

26. Prins $M$, Meadows $G$, Bobevski I, Graham A, Verhaak P, Van der Meer K, Penninx B, Bensing J: Perceived need for mental health care and barriers to care in the Netherlands and Australia. Soc Psychiat Epidemiol .
27. Ronalds C, Creed F, Stone K, Webb S, Tomenson B: Outcome of anxiety and depressive disorders in primary care. Br J Psychiatry 1997, 171:427-433

28. Spijker J: Care utilization and outcome of DSM-III-R major depression in the general population. Results from the Netherlands Mental Health Survey and Incidence Study (NEMESIS). Acta Psychiatrica Scandinavica 2001, 104, Jul-24.

29. Spijker J, Bijl RV, de Graaf R, Nolen WA: Determinants of poor 1-year outcome of DSM-III-R major depression in the general population: results of the Netherlands Mental Health Survey and Incidence Study (NEMESIS). Acta Psychiatrica Scandinavia 2001, 103:122-130.

30. Sargeant JK, Bruce ML, Florio LP, Weissman MM: Factors associated with 1year outcome of major depression in the community. Arch Gen Psychiatry 1990, 47:519-526.

31. Ormel J, Oldehinkel T, Brilman E, vanden Brink W: Outcome of depression and anxiety in primary care. A three-wave 3 1/2-year study of psychopathology and disability. Arch Gen Psychiatry 1993, 50:759-766.

Pre-publication history

The pre-publication history for this paper can be accessed here: http://www.biomedcentral.com/1471-244X/10/86/prepub

doi:10.1186/1471-244X-10-86

Cite this article as: van Beljouw et al:: The course of untreated anxiety and depression, and determinants of poor one-year outcome: a oneyear cohort study. BMC Psychiatry 2010 10:86.

\section{Submit your next manuscript to BioMed Central and take full advantage of:}

- Convenient online submission

- Thorough peer review

- No space constraints or color figure charges

- Immediate publication on acceptance

- Inclusion in PubMed, CAS, Scopus and Google Scholar

- Research which is freely available for redistribution

Submit your manuscript at www.biomedcentral.com/submit
C) Biomed Central 